\title{
Systematic Evaluation of Kriging and Inverse Distance Weighting Methods for Spatial Analysis of Soil Bulk Density
}

\author{
A.H. Sajid ${ }^{1 *}$, R.P. Rudra ${ }^{2}$ and G. Parkin ${ }^{3}$ \\ 'Graduate Student, School of Engineering, University of Guelph, Guelph, ON N1G 2W1Canada \\ 'Professor, School of Engineering, University of Guelph, Guelph ON N1G 2W1Canada \\ ${ }^{3}$ Associate Professor, School of Environmental Sciences, University of Guelph, Guelph, ON N1G 2W1 Canada \\ "Email: asajid@alumni.uoguelph.ca \\ http://dx.doi.org/10.7451/CBE.2013.55.1.1
}

Sajid, A.H., R.P. Rudra and G. Parkin. 2013. Systematic Evaluation of Kriging and Inverse Distance Weighting Methods for Spatial Analysis of Soil Bulk Density. Canadian Biosystems Engineering/Le génie des biosystèmes au Canada 55: 1.1-1.13. Spatial interpolation methods are frequently used to characterize spatial phenomena in soil properties over various spatial scales; however, it is very difficult to select the best interpolation method. No specific standards or tests are available to determine the "appropriateness" of an interpolation model. This study focused on evaluation of the performance of two widely used interpolators: kriging and inverse distance weighting (IDW) for the spatial analysis of soil bulk density. Predicted values by both interpolation models were compared with the observed data and analyzed using various indices. Results indicated that both interpolation methods do not reflect true variation of bulk density. Both models, however, performed equally well for spatial analysis with almost the same accuracy, precision and consistency with a difference of less than $1.0 \%, 0.5 \%$ and $2.0 \%$, respectively. Inverse distance weighting method, simpler than kriging method, gives competitive and somewhat superior results when an optimal power value is used. No relation was found among coefficient of variation, skewness and kurtosis in selecting an appropriate interpolation method for spatial description or selecting a power value for IDW method or a semivariogram model for the kriging method. This study has provided an example of an approach to systematically evaluate the performance of one or more spatial interpolation methods. By employing the validation indices used in this study, any interpolation method can be assessed to accurately describe any spatial data set from the field. Keywords: Kriging, inverse distance weighting, interpolation, spatial analysis, validation indices

Les méthodes d'interpolation spatiale sont fréquemment utilisées pour caractériser des phénomènes spatiaux au niveau des propriété des sols à des échelles différentes. Il peut cependant s'avérer difficile de sélectionner la meilleure méthode d'interpolation puisqu'il n'existe pas de normes spécifiques ou de tests pour déterminer le modèle d'interpolation le plus approprié. Cette étude a porté sur l'évaluation de la performance de deux méthodes populaires : le krigeage et la pondération de la distance inverse (IDW) pour l'analyse spatiale de la densité apparente des sols. Les valeurs prédites par ces deux modèles d'interpolation ont été comparées avec les données observées et analysées par différents équipements. Les résultats ont démontré que les deux méthodes d'interpolation ne permettaient pas de représenter adéquatement la variation réelle de la densité apparente.
Cependant, les deux modèles ont donné de bons résultats pour l'analyse spatiale et ce, avec presque la même exactitude, précision et uniformité et des différences respectives de moins de $1,0 \%, 0,5 \%$ et $2,0 \%$. Plus simple d'utilisation que la méthode de krigeage, la méthode de la pondération de la distance inverse a donné des résultats comparables et presque supérieurs lorsque la valeur de puissance optimale était utilisée. Aucune relation n'a été trouvée entre le coefficient de variation, l'asymétrie et l'aplatissement lors de la sélection d'une méthode appropriée d'interpolation pour la description spatiale ou la sélection de la valeur de puissance pour la méthode IDW ou un modèle semivariogramme pour la méthode de krigeage. Cette étude a fourni un exemple pour une approche d'évaluation systématique de la performance d'une ou de plusieurs méthodes d'interpolation spatiale. En recourant aux indices de validation utilisés dans cette étude, toute méthode d'interpolation peut être évaluée pour décrire précisément tout ensemble de données spatiales mesurées au champ. Mots clés: Krigeage, pondération de distance inverse, interpolation, analyse spatiale, indices de validation

\section{INTRODUCTION}

Selection of an appropriate interpolation method in hydrology is a complex procedure because many hydrologic variables such as soil properties affecting hydrologic processes are spatially heterogeneous and are often based on far from optimal sampling density and with significant noise or discontinuities. Data measurement accuracy, data density, data distribution and spatial variability are the factors having the greatest influence on interpolation accuracy (MacEachren and Davidson 1987). There is no set of specific standards or test or established rules that can be used to select an appropriate interpolation method. The performance of an interpolation method is usually assessed and compared using cross validation. The ultimate goal of cross validation is to increase credibility and gain sufficient confidence about an interpolation method, and to ensure that predictions reflect the most likely true outcome, particularly real spatial variability. The performance of the interpolation method is considered acceptable when the error is small and the variance is low. Range, variance, and correlation are the important attributes often considered for selection of a spatial interpolator. Lam (1983) reviewed point interpolation techniques and reported that various methods have 
individual advantages and disadvantages, and the choice of an interpolation model depends largely on the nature and quality of original data, the degree of accuracy desired, and the amount of computational effort affordable. She concluded that the performance of point interpolation models depends upon the density, spatial arrangement of the data points, and the complexity of the data.

Many interpolation and approximation methods have been developed to predict values of spatial phenomena at un-sampled locations. Typical examples are conditions based on geostatistical concepts (kriging model), locality (nearest neighbour and finite element methods), smoothness and tension (splines), or ad-hoc functional forms (polynomials). The interpolation techniques commonly used in hydrology include inverse distance weighting (IDW) and kriging (Kravchenko 2003; Franzen and Peck 1995). Both methods estimate value of a parameter at unsampled locations based on the measurements from the surrounding locations with certain weights assigned to each of the measurements. Inverse distance weighting is easier to implement, while kriging is more time-consuming and cumbersome; however, kriging generally provides a more accurate description of the data spatial structure, and produces valuable information about estimation error distributions (Kravchenko and Bullock 1999). A number of studies (Kravchenko 2003; Mueller et al. 2001; Gotway et al. 1996; Wollenhaupt et al. 1994; Warrick et al. 1988; Laslett et al. 1987) have compared the performance of kriging and IDW methods, however, the results are rather contradictory (Kravchenko 2003; Lapen and Hayhoe 2003; Mueller et al. 2001; Schloeder et al. 2001).

Kriging, a stochastic technique, is an exact interpolator. Some classify kriging as a statistical technique; many consider it a geostatistical technique (Caruso and Quarta 1998) and others take it as an analytical method (Delfiner 1976). Kriging is an interpolator when applied for estimation wherein if the estimation location coincides with a sample location, the estimation method returns, as the estimate, the exact data value for the sample location (Burrough and McDonnell 1998; Carr 1995). In kriging, selection of the semivariogram model and estimation of its parameters (range, sill) are still controversial (Goovaerts 1998; McBratney and Webster 1986). Several methods have been proposed, ranging from full black-box procedures (automatic) to visual approaches. In the black-box procedure, choice of a model and its fitting are automatic, whereas in visual approaches, a model is subjectively selected based on graphical evaluation. The values of residual sum of squares (RSS) and coefficient of determination $\left(\mathrm{R}^{2}\right)$ are frequently used to rank alternate semivariogram models. Regardless of the fitting procedure adopted, the main objective is to build a permissible semivariogram model that captures the major spatial features of the variable (Goovaerts 1998).

Inverse distance weighting, also called inverse distance squared method and contouring, is also an exact interpolator, where the maximum and the minimum values in the interpolated surface can only occur at sample points. It is a deterministic estimation method where values at unsampled points are determined by a linear combination of values at known sampled points. As in kriging, IDW employs a linear weighted combination of sample values that gives more weight to closer samples and less weight to distant samples. The technique does not make assumptions about spatial relationships except the basic assumption that nearby points ought to be more closely related than distant points to the value at the interpolated location. The performance of the IDW method depends on power function, nearest neighbours and search radius. The power function, $p$, controls the significance of known points on the interpolated values, based on their distance from the output point. The choice of $\mathrm{p}$ value is arbitrary and coefficient of variation, skewness and kurtosis of the data sets may affect optimum $\mathrm{p}$ value (Mueller et al. 2001; Kravchenko and Bullock 1999; Gotway et al. 1996; Weber and Englund 1994).

The performance of interpolation techniques is evaluated using validation indices. A few validation indices include cross validation (Carr 2002), mean prediction error (Vos et al. 2005; Huang et al. 2003), mean absolute error, (Brounder et al. 2005; Naoum and Tsanis 2004), mean squared prediction error, (Schloeder et al. 2001; Voltz and Webster 1990), and root-mean-squared prediction error (Vos et al. 2005; Bishop and McBratney 2001). Besides commonly used scatter-plot, cross validation and coefficient of determination, many accuracy, precision, and consistency indices have been reported in the literature. Some of the indices are: errors/residuals/prediction or estimation errors; bias/mean errors/average errors/Kriged average errors/mean prediction or estimation errors; mean absolute errors/mean of absolute residuals; standard deviation absolute errors; mean squared errors; root-meansquared errors/root-mean-squared prediction errors/kriged reduced mean squared errors; mean of standardized residual error/ reduced mean/mean standardized prediction error; variance of standardized residual errors/reduced variance; goodness-of-fit prediction errors/expected variance/coefficient of efficiency; mean square deviation ratio/mean standardized square errors/standardized mean squared error/mean standardized prediction error/root mean deviation ratio/Kriged reduced mean square error/mean kriging variance; determination index; and index of agreement (Bishop and McBratney 2001; Schloeder et al. 2001; Ella et al. 2001; Kitanidis 1997; Gotway et al. 1996; Laslett 1994; Weber and Englund 1994; Voltz and Webster 1990; Woldt 1990; Yates and Yates 1990; Isaaks and Srivastava 1989; Warrick et al. 1988; Laslett et al. 1987; Agterberg 1984; Gambolati and Volpi 1979).

It is well recognized that a complete assessment of model performance should include at least one "goodnessof-fit" or relative error measurement (e.g., coefficient of efficiency, E or index of agreement, d) and at least one absolute error measure (e.g., root-mean-squared errors, RMSE or mean absolute errors, MAE) with additional 
supporting information (e.g., a comparison between the observed and simulated mean and standard deviation). Legates and McCabe (1999) concluded that correlationbased measures $\left(r, R^{2}\right)$ are inappropriate and should not be used to evaluate the goodness-of-fit of model simulation. They recommended that either modified coefficient of efficiency (E1) or modified index of agreement (d1) be used in lieu of correlation-based measures $\left(r\right.$ or $\left.R^{2}\right)$ to provide a relative assessment of model performance. Also, observed and modeled means and standard deviation, as well as MAE or RMSE (or probably both) should be reported. Use of absolute error measure (MAE, RMSE) provides an evaluation of the error in the units of the variable, which often can provide more information about model efficiency than can be gleaned from the use of relative error or goodness-of-fit measures. Mean absolute error is slightly preferred over root-mean-squared errors (RMSE) when large outliers are present.

Willmott (1981; 1984) partitioned total errors (RMSE2) into average "systematic" errors (RMSEs) and "unsystematic" errors (RMSEu). Huang et al. (2003) tested models based on the percentage of mean prediction errors (MPE) to the observed mean; however, there is no consistent rule of thumb to assess if prediction models' results are accurate enough to be acceptable. For example, Freese (1960) took an allowable error of $\pm 7 \%$. Mowrer and Frayer (1986) suggested that the coefficient of variation (CV) of interpolated data should not exceed $20 \%$. Gaertner et al. (1996) and McRoberts (1996) used a guideline of within $\pm 20 \%$ of the mean. Pillsbury et al. (1995) used an allowable error of $\pm 12 \%$. In Alberta, a $\pm 10 \%$ prediction error at $95 \%$ of confidence interval was used in several studies. Huang et al. (2003) reported that most researchers used thresholds for model acceptance between 10 and 20\% of the observed mean at $95 \%$ of confidence interval. For instance, Prevost (2004) accepted a relative prediction error (SDPE2/MSPE) of 20\% for bulk density. For highly accurate calculations, prediction errors should be below $10 \%$ (Vos et al. 2005).

The literature review provided above indicates that there is a need for a comprehensive and systematic approach to evaluate the accuracy and acceptability of an interpolation method used to describe spatial variability of soil and hydraulic parameters. Therefore, this study was initiated for in-depth review of various validation indices available for evaluation of interpolators used in agricultural hydrology. The specific objective of this study was to evaluate the performance of two widely used interpolators, kriging and IDW, for spatial interpolation of measured soil bulk density. An accurate estimation of the spatial variability in soil bulk density is important as it affects total porosity, degree of compaction and identification of runoff susceptible conditions. The evaluation of two interpolators was conducted comparing the predicted bulk density value with the observed bulk density values using scatter plot, accuracy, precision, consistency, systematic and unsystematic errors, and mean prediction error.

\section{MATERIALS AND METHODS}

\section{Study area}

The experimental field is located at Guelph Turfgrass Institute and Environmental Research Centre, University of Guelph, Guelph, Ontario, Canada. The soil texture was sandy loam that had good internal drainage. The field had a relatively uniform slope of about $6 \%$ along the field length. The field was under grass for ten years prior to tillage in 1999. The data on soil physical properties and hydraulic characteristics collected by Gupta (2002) were used in this study.

The field was divided into 91 blocks of $8 \times 8 \mathrm{~m}$ (a regular 13 cells by 7 cells grid with a distance between sampling locations at the cell centre of $8 \mathrm{~m}$ ). The data on soil physical properties and hydraulic characteristics were collected during Fall 1999 and Summer 2000. Details of sample collection and bulk density measurement method are given in Gupta (2002). In brief, soil samples were obtained by pounding a stainless steel soil sampler of 0.25 $\mathrm{m}$ long by $0.07 \mathrm{~m}$ diameter into the soil, approximately in the centre of each square block. Soil samples were oven dried at $105^{\circ} \mathrm{C}$ for 24 hours to determine dry soil mass for bulk density calculation.

\section{Analysis procedures}

The soil dry bulk density data were interpolated at $4 \mathrm{~m}$ and $1 \mathrm{~m}$ grid size by kriging and IDW methods. Analysis of the observed and interpolated soil dry bulk density was completed in five calculation steps: distributions of values using standard statistics and inter-quartile range; frequency distributions, normality and detection of outliers; transformation of data to logarithmic form, where necessary; application of the two interpolation methods on the data; and evaluation and validation of predicted values based on cross-validation, accuracy, precision, consistency, systematic and unsystematic errors, and MPE to the observed mean. The geostatistical software, $\mathrm{GS}+{ }^{\mathrm{TM}}$, GeoStatistics for the Environmental Sciences, Version 5.3.2 of Gamma Design Software, Michigan, USA, was used for both kriging and IDW models.

Kriging analysis An omni-directional variogram was used for kriging. A large directional tolerance $\left(22.5^{\circ}\right)$ was set so that the direction of any particular separation distance, $\mathrm{h}$, becomes unimportant. Ordinary kriging was used to model the spatial variability of dry bulk density. Webster and Oliver (2001) and Johnson et al. (1996) reported that the ordinary kriging of a single variable is the most robust and frequently used method for its accurate accounting of data fluctuations and consideration of a global trend over the study region.

For the semivariogram model, an intermediate approach, consisting of an automatic (least-square) estimation of parameters of models, was chosen. The main objective was to minimize residual sum of squares (RSS) of differences between experimental and model semivariogram values. The approach recommended by Carr (2002) and Deutsch (2002) was used to select a lag interval. They suggested a lag interval should be equal to 
the minimum sampling resolution (Carr 2002) or an interval that coincides with the data spacing may be used for regular grids (Deutsch 2002). Active lag distances, ranging from one-third (Golden Software Inc. 2002), 50\% (Deutsch 2002) and 80\% (Gamma Design Software 2002) of the longest distance, were tried to fit the optimal semivariogram model to the field data.

Active lag distances, ranging from $40 \mathrm{~m}$ to $96 \mathrm{~m}$ (multiple of $8 \mathrm{~m}$ ), were used to fit the semivariogram model to field data by keeping the lag interval constant at the original sampling resolution of $8 \mathrm{~m}$. Based on the lowest RSS and relatively higher $\mathrm{R}^{2}$ values, an optimal active lag distance was then chosen. The chosen active lag distance was again tested with the different uniform lag intervals that coincided with the sampling resolution $(2,4$, and $8 \mathrm{~m}$ ). Finally, based on the optimal combination of the active lag distance and uniform lag interval, a semivariogram model was selected that had the lowest RSS values, followed by the higher $\mathrm{R}^{2}$ value.

Inverse distance weighting analysis For IDW interpolator, different combinations of nearest neighbours, search radii and power functions were tested to get optimal results. In the beginning, distances to the nearest neighbours and radius were fixed at $16 \mathrm{~m}$ and $107.33 \mathrm{~m}$ (maximum diagonal distance), respectively, consistent with the traditional approach to construction an IDW model (Kravchenko and Bullock 1999). Then, different values for $\mathrm{p}$ ( 1 to 30 , including fractions), were tested for minimum values of standard errors of prediction (SEp) and standard errors (SE) with relatively high $\mathrm{R}^{2}$. In the next step, keeping the selected $p$ value and search radius constant, different numbers of nearest neighbours were used to observe any change in SE, SEp and $\mathrm{R}^{2}$ values.
Finally, based on the best agreement between lower SEp and $\mathrm{SE}$ values, and relatively high $\mathrm{R}^{2}$ value, optimal values of $\mathrm{p}$ and nearest neighbours were selected to interpolate dry soil bulk density data using IDW.

Results of both models were compared and evaluated based on cross validation (scatter-plot), accuracy errors, precision errors and consistency as previously discussed in the Evaluation Criteria section. A list of equations used is given in Sajid (2009) and is available from the corresponding author.

\section{RESULTS AND DISCUSSION}

Univariate statistical analysis of bulk density (BD) data for Fall 1999 and Summer 2000 are presented in Table 1. The mean of the bulk density for Fall 1999 was about 9\% lower than the mean obtained for Summer 2000. The medians and modes of both time periods' data were almost identical to their respective arithmetic means. The lower coefficient of variation for the both years indicates a homogeneous data set with small spatial and temporal variations. Bulk density data for both years were skewed to the left indicating outliers were to the left of the mean (lower than the mean). Bulk density data for 1999 and 2000 had positive kurtosis and passed the KolmogorovSmirnov Test for normality with $\mathrm{D}$ values of 0.138 and 0.119 , respectively ( $\mathrm{D}$ values for 91 data points should be less than 0.142 from a normal distribution: Kanji 1993).

The application of the modified Z-scores method and boxplot method (Tukey 1977) indicated one observation of bulk density during 1999 and four observations during 2000 were outliers. Outliers were not excluded for further analysis, as these were field observations (Isaak and Srivastava 1989).

Table 1. Summary statistics of observed and interpolated data for bulk density.

\begin{tabular}{|c|c|c|c|c|c|c|}
\hline \multirow{3}{*}{$\begin{array}{l}\text { Summary } \\
\text { Statistics }\end{array}$} & \multicolumn{5}{|c|}{ Bulk Density $\left(\mathrm{Kg} \mathrm{m}^{-3}\right)$} & \\
\hline & \multicolumn{3}{|c|}{1999} & \multicolumn{3}{|c|}{2000} \\
\hline & Observed & KRG & IDW & Observed & KRG & IDW \\
\hline Minimum & 1060.00 & 1259.92 & 1227.04 & 1166.00 & 1408.02 & 1381.93 \\
\hline Maximum & 1700.00 & 1550.74 & 1597.82 & 1830.00 & 1699.47 & 1745.05 \\
\hline Data Size & 91 & 91 & 91 & 91 & 91 & 91 \\
\hline Mean & 1430.77 & 1429.83 & 1429.44 & 1573.36 & 1568.60 & 1569.59 \\
\hline Mode & 1500.00 & 1416.00 & 1425.00 & 1540.00 & 1568.00 & 1590.00 \\
\hline Median & 1450.00 & 1433 & 1431 & 1580 & 1570 & 1571 \\
\hline Standard Deviation & 114.85 & 55.34 & 66.93 & 124.17 & 58.15 & 68.10 \\
\hline Variance & $1.3 \mathrm{E}+04$ & $3.0 \mathrm{E}+03$ & $4.5 \mathrm{E}+03$ & $1.5 \mathrm{E}+04$ & $3.4 \mathrm{E}+03$ & $4.6 \mathrm{E}+03$ \\
\hline Coefficient of Variance & 0.080 & 0.039 & 0.047 & 0.079 & 0.037 & 0.043 \\
\hline Skewness & -0.59 & -0.21 & -0.19 & -0.96 & -0.17 & -0.25 \\
\hline Kurtosis & 0.72 & 0.46 & 0.64 & 2.04 & 0.29 & 0.65 \\
\hline Lower Quartile $\left(\mathrm{Q}_{0.25}\right)$ & 1363.00 & 1401.08 & 1388.08 & 1527.00 & 1529.73 & 1526.51 \\
\hline Upper Quartile $\left(\mathrm{Q}_{0.75}\right)$ & 1500.00 & 1456.62 & 1462.01 & 1648.80 & 1599.41 & 1609.83 \\
\hline SE of Mean & $1.2 \mathrm{E}+01$ & $5.8 \mathrm{E}+00$ & $7.0 \mathrm{E}+00$ & $1.3 \mathrm{E}+01$ & $6.1 \mathrm{E}+00$ & $7.1 \mathrm{E}+00$ \\
\hline $95 \%$ CI for Mean & 23.92 & 11.53 & 13.94 & 25.86 & 12.11 & 14.18 \\
\hline K-Smirnov Test & 0.138 & 0.083 & 0.089 & 0.119 & 0.093 & 0.086 \\
\hline
\end{tabular}




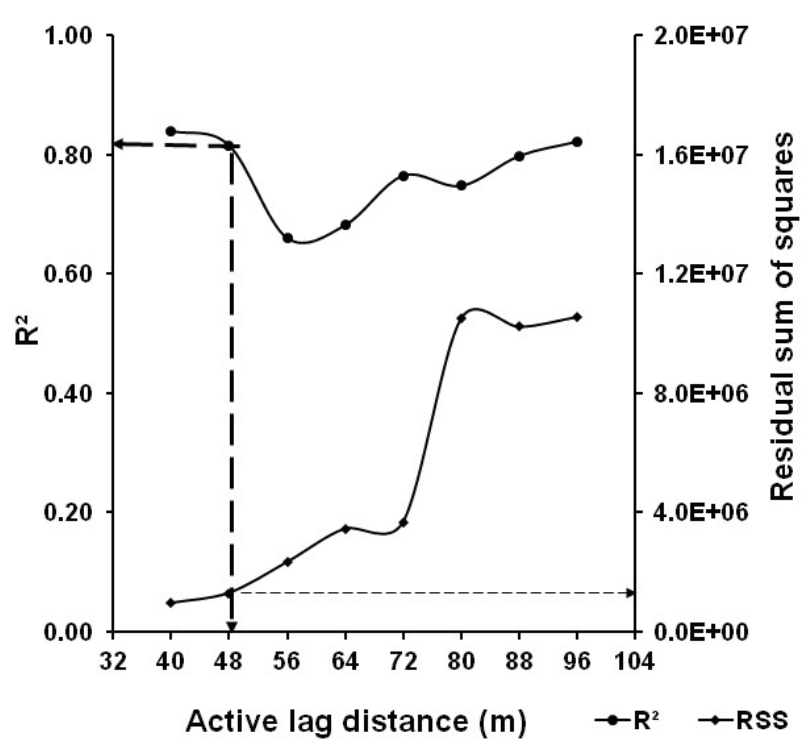

Fig. 1. Relationship between residual sum of squares, coefficient of determination, and active lag distance at fixed uniform lag interval of $8 \mathrm{~m}$ for bulk density for 1999 .

\section{Kriging}

Preliminary semi-variogram model screening consistently showed that an exponential model fits best to the bulk density data. Figure 1 shows a relationship between residual sum of squares (RSS), coefficient of determination $\left(\mathrm{R}^{2}\right)$ and active lag distance (ALD) at a constant uniform lag interval of $8 \mathrm{~m}$ for bulk density data for Fall 1999 using an exponential model. The minimum RSS $(9.59 \mathrm{E}+05)$ and the highest $\mathrm{R}^{2}$ values $(0.84)$ were observed at an ALD of $40 \mathrm{~m}$. The next minimum RSS $(1.30 \mathrm{E}+06)$ and the higher $\mathrm{R}^{2}$ values $(0.82)$ were at ALD of $48 \mathrm{~m}$. These results show that RSS increases with ALD. The lowest value of RSS was at ALD of $40 \mathrm{~m}$, reached maximum value at ALD of $80 \mathrm{~m}$ and then became stable thereafter. The change in $\mathrm{R}^{2}$ with ALD did not show such consistent trend. Based on the lowest RSS and highest $\mathrm{R}^{2}$, an active lag distance of $40 \mathrm{~m}$ was the best choice; however, the combination of $40 \mathrm{~m}$ ALD with $8 \mathrm{~m}$ lag interval created only four data points, which were not sufficient for a regression analysis. Literature suggests a minimum of five to six data points to fit a curve or model to data. Due to this reason, ALD of $48 \mathrm{~m}$ having the next lowest RSS and highest $\mathrm{R}^{2}$ was selected and this combination created five data points for the regression analysis. Keeping the ALD fixed at $48 \mathrm{~m}$, different uniform lag intervals (ULI) of 2, 4, and $8 \mathrm{~m}$ were tested to refit an exponential semivariogram model and the results are presented in Fig. 2. These results indicate that RSS is maximum at ULI of $2 \mathrm{~m}$ and decreases with an increase in ULI from 2 to $8 \mathrm{~m}$. On the other hand, the value of $\mathrm{R}^{2}$ was minimum (0.28) at ULI of $4 \mathrm{~m}$ and maximum (0.82) at 8 $\mathrm{m}$ for an exponential model. Based on the optimal combination of the lowest RSS $(1.30 \mathrm{E}+06)$ and the highest

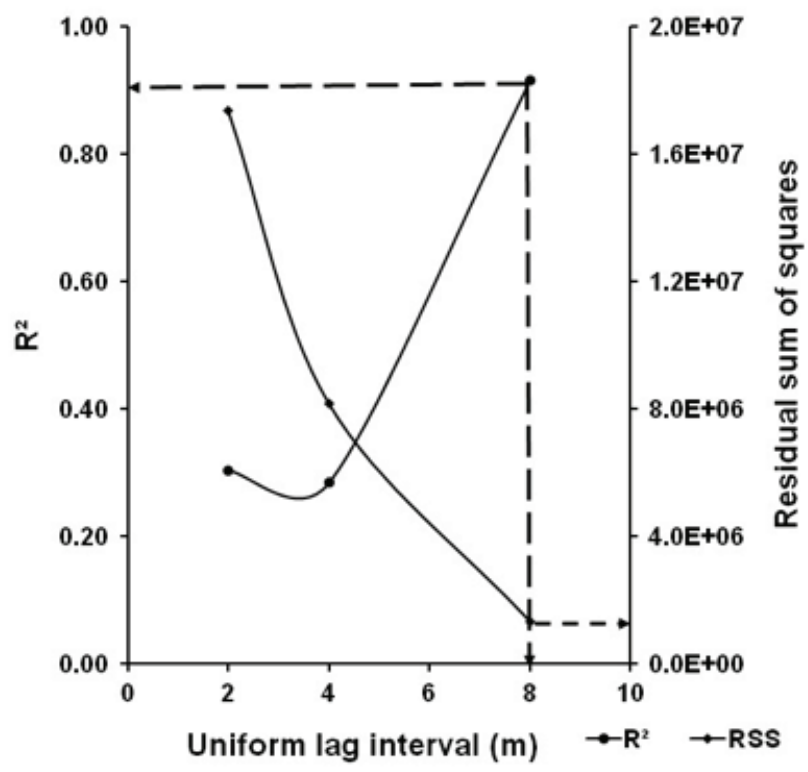

Fig. 2. Relationship between residual sum of squares, coefficient of determination, and uniform lag interval at fixed active lag distance of $48 \mathrm{~m}$ for bulk density for 1999 .

$\mathrm{R}^{2}$ (0.82), an exponential semivariogram model with an ALD of $48 \mathrm{~m}$ and a ULI of $8 \mathrm{~m}$ was selected for further analysis of bulk density for Fall 1999. Using the same approach for the 2000 data also resulted in an exponential model with ALD of $48 \mathrm{~m}$ and a ULI of $8 \mathrm{~m}$.

Figures 3 and 4 show plots of exponential semivariogram models for bulk density for 1999 and 2000, respectively. The effective range (A) is $32 \mathrm{~m}$ for 1999 and $12 \mathrm{~m}$ for 2000 . Higher range in the bulk density for fall 1999 resulted in larger spatial correlation in 1999 than in 2000. The range also gives an indication for minimum spacing of sample collection. It is suggested that average spacing for collection of field data should be 3-5 times less than the range; otherwise the resources will be wasted if the samples are taken at a closer interval than this range. Samples taken further apart will not give enough points for semi-variogram analysis to determine a meaningful spatial relationship. These results indicate that the sampling separation distance of $8 \mathrm{~m}$ was adequate for fall 1999 but inadequate for summer 2000. Sampling intervals should have been between $6.4-10.7 \mathrm{~m}$ for fall 1999 and $2.5-4.0$ $\mathrm{m}$ for Summer 2000.

According to Barnes (1999), sill can be used to approximate the statistical variance of the observed data. The value of the sill for bulk density was $1.30 \mathrm{E} 0+4\left(\mathrm{~kg} \mathrm{~m}^{-}\right.$ $\left.{ }^{3}\right)^{2}$ for both seasons indicating that, at distances greater than $32 \mathrm{~m}$ for 1999 and $12 \mathrm{~m}$ for 2000, the bulk density data pairs exhibit a semi-variance that oscillates with a value of about $1.30 \mathrm{E}+04\left(\mathrm{~kg} \mathrm{~m}^{-3}\right)^{2}$.

The ratio of nugget to total semivariance, N/S ratio, expressed as a percentage (Goderya et al. 1996; Cambardella et al. 1994) was used as a characteristic of the strength in spatial structure of the data. A small $N / S$ ratio 


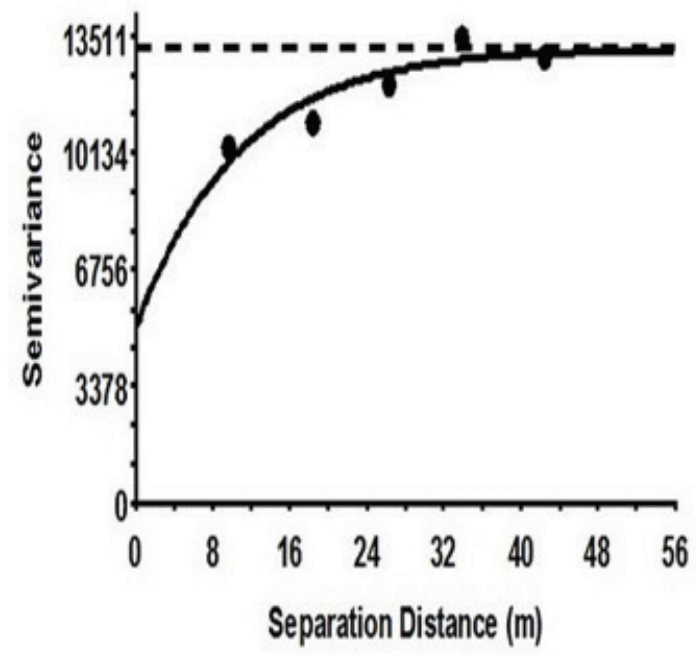

Fig. 3. Exponential semi-variogram model for bulk density for 1999.

and large spatial correlation range usually indicate a higher accuracy in estimating, predicting, or mapping the variable (Isaaks and Srivastava 1989). Suggested N/S ratios generally varies from 0.01 to 1.0 with the majority of reported variograms having $\mathrm{N} / \mathrm{S}$ ratios of 0.1 (strong spatial structure) to 0.6 (weak spatial structure). A higher value of $\mathrm{N} / \mathrm{S}$ ratio 0.6 means that $60 \%$ of the variability in the data consists of un-explainable, short distance, random variation - corresponding to a weak spatial structure, respectively (Kravchenko 2003; Muller et al. 2001; Cambardella and Karlen 1999; Chang et al. 1999). In this study, the N/S ratio was 0.38 for 1999 and 0.79 for 2000, suggesting a stronger spatial structure of the bulk density in 1999 than in 2000 . About $38 \%$ of the variability in the bulk density in the Fall 1999 data consists of un-explainable, short distance, random variation. The lower value in 1999 than in 2000 may be the result of tillage prior to sampling in 1999 as tillage should lead to a more homogeneous shallow soil layer with less random bulk density. This result seems to be in contradiction to the slightly lower $\mathrm{CV}$ for bulk density for 2000; it is possible that the data may have a larger range yet still have stronger spatial structure. This result reinforces the necessity to examine the relative spatial structure of data and not just the variation about the mean when describing data variability. Strong spatially dependent properties may be controlled by intrinsic variations in soil characteristics, such as texture and mineralogy (Goderya et al. 1996; Cambardella et al. 1994). Extrinsic variations (tillage, fertilizers etc.) may control the variability of the weakly spatially dependent parameters. Seasonal variations and extrinsic factors probably contributed to the observed differences in N/S ratio in this study.

\section{Inverse Distance Weighting}

Figure 5 shows a relationship between $\mathrm{SE}_{\mathrm{p}}, \mathrm{SE}$ and $\mathrm{R}^{2}$ with $p$ for a constant value of nearest neighbours (16) and

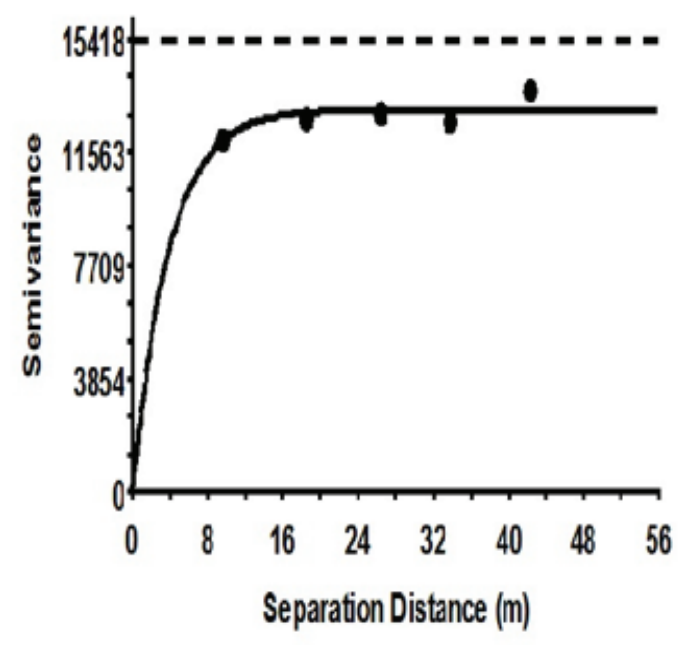

Fig. 4. Exponential semi-variogram model for bulk density for 2000.

search radius $(107 \mathrm{~m})$ for bulk density for 1999 . The range in $\mathrm{SE}_{\mathrm{p}}$ from 101 to 105 was not very sensitive to $p$. The $\mathrm{SE}_{\mathrm{p}}, 105$ at unit value of $p$ equal to one, started decreasing with an increase in the value of $p$ and became stable when $p$ was $\geq 4$ (Fig. 5). The $\mathrm{SE}$ was greatest at the lowest value of $p$ of 1 . It started decreasing with an increase in $p$ and became almost stable for $p \geq 5$. This indicates that any value of $p \geq 5$, could be selected for interpolation of the bulk density data. On the other hand, $\mathrm{R}^{2}$, lowest when $p$ was equal to 1 , started increasing with an increase in $p$ and reached a maximum (0.23) when $p$ was equal to 5 and then became stable. Figure 6 shows a relationship between regression coefficient (slope), Y-intercept and power values for constant values of nearest neighbours (16) and search radius $(107 \mathrm{~m})$. The slope of this regression line showed a decreasing trend (from 1.02 to 0.75 ) with an increase in the value of $p$ and became independent for $p \geq$ 13. The Y-intercept, on the other hand, showed an increasing trend from -28 to 355 with the change in the values of $p$ from 1 to 15 . Similar results were obtained when search radius was set at $56 \mathrm{~m}$. Based on the optimal combination of lower values of $\mathrm{SE}_{\mathrm{p}}$ (101), SE (0.16) and higher value of $\mathrm{R}^{2}(0.23)$, a power value of 5 was selected to check optimal numbers of the nearest neighbours. Figure 7 shows relationship between $\mathrm{SE}_{\mathrm{p}}, \mathrm{SE}$ and $\mathrm{R}^{2}$ with different numbers of nearest neighbours for a constant $p$ value of 5 and a search radius $107 \mathrm{~m}$ for fall 1999. These results indicate that $S E_{p}$ and $R^{2}$ were not sensitive to the nearest neighbour values. The standard errors (SE), however, showed a marginally increasing trend from 5 to 10 values of nearest neighbours and then became stable. The $Y$-intercept showed a marginally decreasing trend and this regression coefficient was found to be independent of the nearest neighbour values. These results suggest that the value of the nearest neighbours should be between 5 and 30 . Based on this analysis, an optimal value $p$, search 


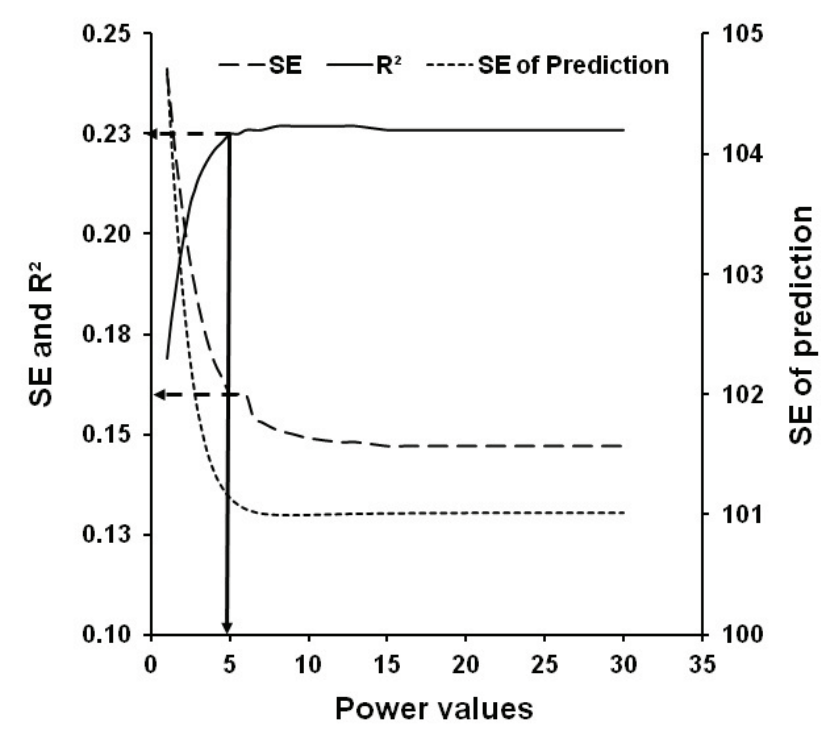

Fig. 5. Relationship between powers values, standard errors of prediction, standard errors, and coefficient of determination with a constant value of nearest neighbours (16) and search radius (107 m) for bulk density for 1999 .

radius and the number of nearest neighbours selected for interpolation of bulk density for Fall 1999 were 5, 107 m and 16 , respectively.

For Summer 2000, the trends in the change in SE with $p$ were similar to the trends observed for Fall 1999; however, its range was different. In $2000, \mathrm{SE}_{\mathrm{p}}$ showed a decreasing trend while $\mathrm{R}^{2}$ had an increasing trend with an increase in $p$ from 1 to 3 and the reverse trend when $p$ was greater than 3 . The $\mathrm{SE}_{\mathrm{p}}$ was found to be in the range of 113 and 115 for different values of $p$. The maximum SE value (0.22) was observed at 1.0 value of $p$ and minimum (0.15) at 17 value of $p$. The $\mathrm{SE}$ was almost stable $(0.17)$ when $p$ was greater than 3 . The value of $\mathrm{R}^{2}$ ranged between 0.17 and 0.14 . The $\mathrm{R}^{2}$ increased from 0.16 (for $p=1$ ) to 0.17 (for $p=3$ ) and then started decreasing and became minimum and stable $(0.14)$ for $p \geq 12$.

For Summer 2000, with a constant value of 16 for the nearest neighbours and search radius of $107 \mathrm{~m}$, the change in slope (regression coefficient) and Y-intercept with $p$ also showed trends, similar to Fall 1999. The slope decreased with an increase in $p$ and became stable for $p \geq$ 10. The $Y$-intercept increased with an increase in $p$ from 1 to 10 and then it became independent. Based on the lower values of $\mathrm{SE}_{\mathrm{p}}$ (113.4), $\mathrm{SE}(0.18)$ and higher value of $\mathrm{R}^{2}$ (0.17), an optimal value of $p$ equal to 3 was selected to check optimal numbers of nearest neighbours. Following the same procedure, optimal values of $p$, search radius and nearest neighbours selected for the interpolation of bulk density for Summer 2000 were 3, $107 \mathrm{~m}$, and 13, respectively.

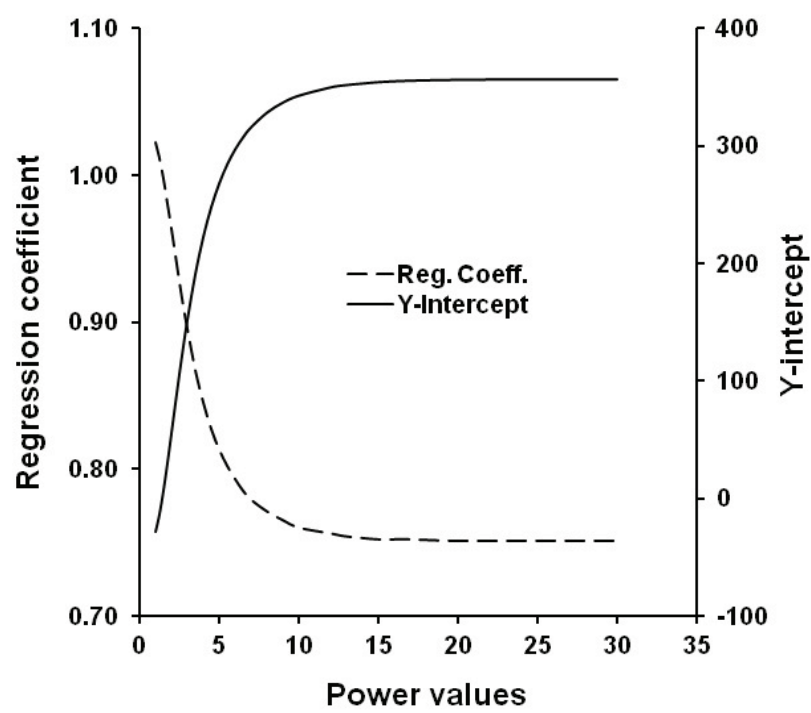

Fig. 6. Relationship between powers values, regression coefficient and $\mathrm{Y}$-intercept with a constant value of nearest neighbours (16) and search radius $(107$ m) for bulk density for 1999.

Comparison and evaluation of Kriging and IDW interpolators

Table 1 shows summary statistics of observed and interpolated bulk density values by kriging and IDW methods and Table 2 shows average absolute accuracy,

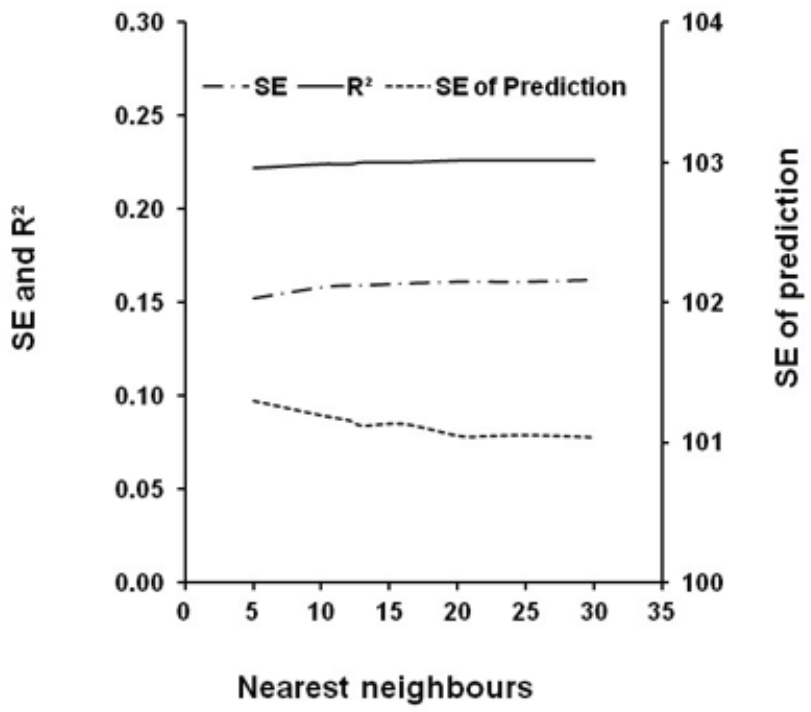

Fig. 7. Relationship between powers values, standard errors of prediction, standard errors, and coefficient of determination with a constant value of nearest neighbours (16) and search radius $(107 \mathrm{~m})$ for bulk density for 1999. 
Table 2. Average absolute accuracy, precision, overall errors, consistency, systematic and unsystematic errors and their proportions, and mean prediction errors to $95 \%$ confidence intervals of mean and observed mean of kriging and inverse distance weighting methods used for spatial analysis of bulk density.

\begin{tabular}{|c|c|c|c|c|}
\hline \multirow{2}{*}{ Cross Validation Indices } & \multicolumn{2}{|c|}{ Bulk Density 1999} & \multicolumn{2}{|c|}{ Bulk Density 2000} \\
\hline & Kriging Method & IDW Method & Kriging Method & IDW Method \\
\hline Average Absolute Accuracy Errors & $2.042 \mathrm{E}+01$ & $2.023 \mathrm{E}+01$ & $2.245 \mathrm{E}+01$ & $2.230 \mathrm{E}+01$ \\
\hline Average Absolute Precision Errors & $2.645 \mathrm{E}+03$ & $2.635 \mathrm{E}+03$ & $3.307 \mathrm{E}+03$ & $3.323 \mathrm{E}+03$ \\
\hline $\begin{array}{l}\text { Average Absolute } \\
\text { Overall Errors } \\
\text { (Accuracy + Precision) }\end{array}$ & $1.333 \mathrm{E}+03$ & $1.327 \mathrm{E}+03$ & $1.665 \mathrm{E}+03$ & $1.673 \mathrm{E}+03$ \\
\hline Average Consistency & 0.61 & 0.62 & 0.61 & 0.62 \\
\hline Average Systematic Errors & $8.886 \mathrm{E}+01$ & $8.245 \mathrm{E}+01$ & $1.004 \mathrm{E}+02$ & $9.556 \mathrm{E}+01$ \\
\hline Average Unsystematic Errors & $4.919 \mathrm{E}+01$ & $5.894 \mathrm{E}+01$ & $5.333 \mathrm{E}+01$ & $6.210 \mathrm{E}+01$ \\
\hline Systematic Errors Proportion (\%) & 77.54 & 66.19 & 77.99 & 70.31 \\
\hline Unsystematic Errors Proportion (\%) & 23.46 & 33.81 & 22.01 & 29.69 \\
\hline MPE to $95 \%$ CI of Mean (\%) & -4 & -6 & -18 & -15 \\
\hline MPE to Observed Mean (\%) & 0 & 0 & 0 & 0 \\
\hline Recommended Model & \multicolumn{2}{|c|}{ IDW } & \multicolumn{2}{|c|}{ IDW } \\
\hline
\end{tabular}

precision, overall errors, consistency, systematic and unsystematic errors and their proportions, MPE to $95 \%$ confidence intervals of mean and observed mean, and recommended model.

Univariate statistical analysis of predicted values shows that the performance of both interpolated models was equally good for both fall 1999 and Summer 2000. Means of the predicted values of bulk density using kriging and IDW methods were similar to the observed mean for both seasons. The range of the predicted values of bulk density by kriging was 1259.92 to $1550.74 \mathrm{~kg} \mathrm{~m}^{-3}$ for 1999 and 1408.02 to $1699.47 \mathrm{~kg} \mathrm{~m}^{-3}$ for 2000 . Inverse distance weighting, on the other hand, predicted the range of bulk density values from 1227.04 to $1597.82 \mathrm{~kg} \mathrm{~m}^{-3}$ for 1999 and 1381.93 to $1745.05 \mathrm{~kg} \mathrm{~m}^{-3}$ for the year 2000 , respectively. The kriging model over-estimated the minimum values by $19 \%$ and $21 \%$, and under-estimated the maximum values by $9 \%$ and $7 \%$ for the years 1999 and 2000, respectively. On the other hand, IDW model over-estimated the minimum value of bulk density by $16 \%$ and $19 \%$, and under-estimated the maximum value by $6 \%$ and $5 \%$ for the both periods. Both interpolators predicted the mode and median similar to the observed value for both seasons. Predicted standard deviations (SD) by both methods were about half of the observed SD values for both seasons. Kriging and IDW predicted coefficients of variation of 0.039 and 0.047 , respectively, which were about $49 \%$ and $59 \%$ of the observed coefficient of variation for fall 1999. Predicted coefficients of variation by kriging and IDW were 0.037 and 0.043 , respectively, which were $47 \%$ and $54 \%$ of the observed coefficient of variation for Summer 2000.

For fall 1999, the predicted SE of mean (used to assess variability) for the bulk density by kriging and IDW were $5.801 \mathrm{E}+00$ and $7.016 \mathrm{E}+00$, respectively, compared to the observed value of $1.204 \mathrm{E}+01$. For Summer 2000, the values of SE of mean were $6.095 \mathrm{E}+00,7.138 \mathrm{E}+00$ and $1.302 \mathrm{E}+01$ for kriging, IDW and observed data, respectively. All predicted SE of mean showed less variability than the observed values. This reduced variability is often referred to as "smoothing" (Hohn 1999). In other words, interpolation models introduced a "smoothing effect" in the predicted values. Also, if predicted SE of mean is close to root-mean-squared prediction error (RMSPE), then the variability in the prediction is correctly assessed. The predicted SE of mean by kriging and IDW methods were less than their RMSPE for bulk density for both $1999(1.02 \mathrm{E}+02)$ and 2000 $(1.14 \mathrm{E}+02)$ datasets, confirming that both prediction methods have a tendency towards underestimation of the variability in comparison to the observed data for both years. The predicted $95 \%$ confidence interval (CI) for means of both methods was also almost identical, indicating that their performance was not substantially different from each other.

Cross validation The cross-validation analysis between the observed bulk density and the bulk density predicted by kriging and IDW models for 1999 and 2000 are given in Figs. 8 and 9. These data for both years show a cluster of points. The cluster is wider for 1999 and more moderately diffused in the middle than for 2000. For 1999, the cluster of observed and predicted values is moderately scattered around the 1:1 line indicating a moderate relationship between predicted and observed bulk density. A few erratic values can be seen due to the presence of one outlier for 1999 and four outliers for 2000. For example, for 1999 , for an observed value of $1060.00 \mathrm{~kg} \mathrm{~m}^{-3}$ for the bulk density the kriging predicted a value of $1356.16 \mathrm{~kg} \mathrm{~m}^{-}$ ${ }^{3}$. Similarly, for the same year, for an observed value of $1450.00 \mathrm{~kg} \mathrm{~m}^{-3}$ the kriging predicted a value $1259.92 \mathrm{~kg}$ $\mathrm{m}^{-3}$. A similar scatter pattern is also visible for the IDW method. The IDW method predicted the same two observed values as $1356.28 \mathrm{~kg} \mathrm{~m}^{-3}$ and $1227.04 \mathrm{~kg} \mathrm{~m}^{-3}$, respectively. This indicates that both models slightly underestimate the higher and overestimate the lower values of bulk density. The regression analysis also 


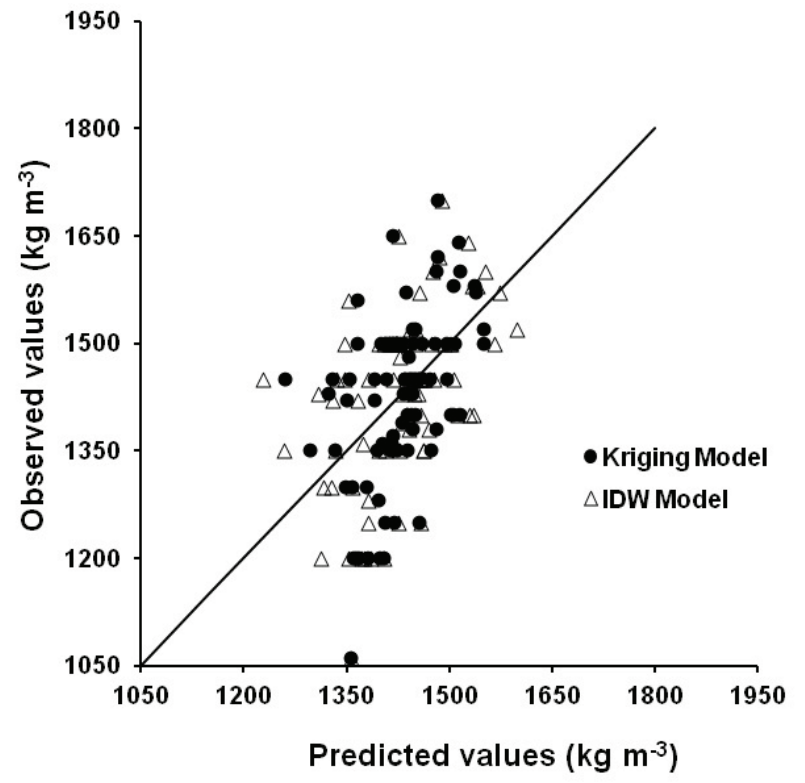

Fig. 8. Cross-validation analysis between the bulk density measured in the field and predicted by the Kriging and IDW model for Fall 1999.

resulted in similar correlation coefficients between the observed and predicted bulk density for both years. Both methods show a moderate positive linear relationship between observed and predicted values. The correlation coefficients between the observed and predicted data from kriging model were 0.46 and 0.40 for 1999 and 2000, respectively. For the IDW method, the correlation coefficients between the observed and predicted values for 1999 and 2000 were 0.47 and 0.41 , respectively.

Accuracy The accuracy of prediction was evaluated by using mean prediction errors (MPE), mean absolute errors (MAE), reduced mean (RM) and coefficient of residual mass (CRM) indices. The MPE for kriging and IDW models for 1999 were $-9.39 \mathrm{E}-01$ and $-1.33 \mathrm{E}+00$, respectively. For 2000 , MPE were $-4.76 \mathrm{E}+00$ from kriging and $-3.78 \mathrm{E}+00$ from IDW methods. The negative MPE indicates that both models under-predict bulk density for both years. Mean prediction errors from kriging model were less for year 1999 but higher for year 2000; however, errors for both models were almost equal based on both years. Based on this index, kriging and IDW methods were able to predict bulk density with similar degree of accuracy.

The MAE between the observed and simulated bulk density by kriging and IDW were $8.07 \mathrm{E}+01$ and $7.96 \mathrm{E}+01$ for 1999, and $8.50 \mathrm{E}+01$ and $8.54 \mathrm{E}+01$ for 2000, respectively. Relatively smaller values of MAE from IDW method for 1999 and kriging method for 2000 indicate their marginal superior accuracy over each other. Based on this criterion, both models also exhibited almost the same performance.

The RM values for kriging and IDW models were 8.18E-03 and -1.16E-02 for 1999 and -3.83E-02 and -

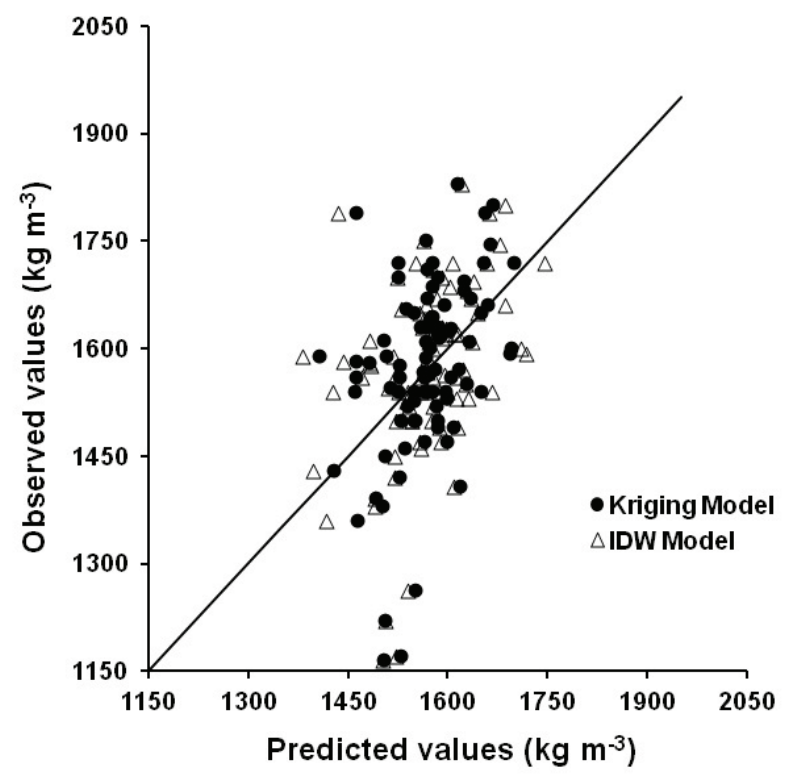

Fig. 9. Cross-validation analysis between the bulk density measured in the field and predicted by the Kriging and IDW model for Summer 2000.

3.04E-02 for 2000, respectively. Lower values of RM suggest less error while the negative values show underprediction of the observed values by both methods. Based on this index, both models are capable for prediction of bulk density; however, kriging is found to be marginally superior for 1999 and IDW for 2000.

The CRM mass values for kriging and IDW models were $6.56 \mathrm{E}-04$ and $9.28 \mathrm{E}-04$ for 1999 and 3.02E-03 and $2.40 \mathrm{E}-03$ for 2000 , respectively. A positive but small value of CRM by both methods indicated slight over-estimation. This index also confirms that prediction errors were relatively less from kriging method for 1999 and IDW method for 2000.

Based on absolute average accuracy errors, both models' results were competitive with less than $1 \%$ difference.

Precision The precision of the simulated bulk density by both methods was evaluated by using standard deviation prediction errors (SDPE), standard deviation absolute errors (SDAE), mean squared prediction errors (MSPE) and root-mean-squared prediction errors (RMSPE) indices. The values of SDPE from both kriging and IDW models were almost equal: $1.02 \mathrm{E}+02$ and $1.14 \mathrm{E}+02$ for 1999 and 2000 , respectively. The values of SDAE were $6.20 \mathrm{E}+01$ and $7.59 \mathrm{E}+01$ from kriging method and $6.31 \mathrm{E}+01$ and 7.59E+01 from IDW method for 1999 and 2000, respectively. Almost equal values of both indices by both methods suggest that they had equal deviation of the prediction errors, resulting in equal precision in predicted values.

The MSPE, an indicator of the magnitude of differences point-by-point, from both the methods were relatively high but the same for 1999 and 2000. The MSPE 
from kriging and IDW were 1.03E+04 for 1999 and $1.29 \mathrm{E}+04$ for 2000 , respectively, less than the observed variance $(1.32 \mathrm{E}+04$ for 1999 and $1.54 \mathrm{E}+04$ for 2000) indicating reasonably precise overall prediction (Voltz and Webster 1990; Woldt 1990).

Because of the similar MSPE values, RMSPE from both methods was also essentially the same for both years $(1.02 \mathrm{E}+02$ for 1999 and $1.14 \mathrm{E}+02$ for 2000). The greater values of RMSPE than their respective MAEs suggest that both methods are reasonably precise. The degree to which RMSPE exceeds MAE indicates the extent to which outliers exist in the data (Legates and McCabe 1999).

Based on average of these indices, both models' results were competitive with less than $0.5 \%$ difference.

Consistency The indices used to evaluate the consistency include index of agreement (d), reduced variance (RV), coefficient of efficiency (E), and root-mean-squared standardized prediction errors (RMSSPE). For both years, $d$ for the IDW method (0.62 for 1999 and 0.57 for 2000) was relatively higher than kriging method ( 0.58 for 1999 and 0.53 for 2000) indicating IDW to be slightly more consistent than the kriging method. However, these values of $d$ indicate that both models have a moderate consistency with the observed values.

The values of RV were the same: 0.78 for 1999 and 0.84 for 2000 for both kriging and IDW methods. These values fall within the suggested range of mean squared deviation ratio, MSDR ( 0.56 to 1.45 ), revealing that both methods performed equally well with acceptable consistency.

The $\mathrm{E}$ from both models is very low but similar in magnitude indicating very little difference between the methods. This index is also an indicator of the proportion of the total variability in the variable that is accounted for by the predicted values (Chatterjee et al. 2000). Both methods explained only $21 \%$ of the total variability for 1999 and $15 \%$ for 2000 .

The RMSSPE, an index to check the consistency between prediction errors and standard deviation of the observed values, were 0.88 and 0.92 from both methods for 1999 and 2000, respectively. These values (close to 1.0) are within the suggested range (0.70 to 1.30$)$ indicating that both models performed equally well with acceptable consistency.

Based on these indices, both methods gave comparable, consistence and acceptable performance with less than $2 \%$ difference.

Systematic and unsystematic errors Following the approach suggested by Willmott (1981), RMSPE or RMSE, were divided into average "systematic" $\left(\mathrm{RMSE}_{s}\right)$ and "unsystematic" $\left(\mathrm{RMSE}_{u}\right)$ to quantify the proportion of systematic and unsystematic errors to the total errors. For good performance of a model, $\mathrm{RMSE}_{s}$ should be relatively small and $\mathrm{RMSE}_{u}$ should approach RMSE.

For 1999, $\mathrm{RMSE}_{s}$ and $\mathrm{RMSE}_{u}$ for kriging method were $8.886 \mathrm{E}+01$ and $4.919 \mathrm{E}+01$, respectively, whereas these errors were $8.245 \mathrm{E}+01$ and $5.894 \mathrm{E}+01$ for IDW method, respectively. Average systematic errors from kriging method were $77 \%$ of the total errors (MSE) and 66\% from IDW method. The proportion of unsystematic errors from kriging method was less $(23 \%)$ than the IDW method (34\%). Average unsystematic errors from IDW were higher and closer to RMSE. Lower average systematic errors and higher unsystematic errors, but closer to RMSE, suggested that IDW method is superior to kriging method for bulk density 1999.

For 2000, $\mathrm{RMSE}_{s}$ and $\mathrm{RMSE}_{u}$ were $1.004 \mathrm{E}+02$ and $5.333 \mathrm{E}+01$ for kriging and $9.556 \mathrm{E}+01$ and $6.210 \mathrm{E}+01$ for IDW method, respectively. Average systematic errors were $78 \%$ and $70 \%$ while average unsystematic errors were $22 \%$ and $30 \%$ of the total errors, respectively. Average systematic errors were lower while unsystematic errors were higher again proving the superiority of the IDW model.

Mean prediction errors to observed mean Values of MPE to the $95 \%$ confidence intervals for observed mean from kriging and IDW methods for bulk density were calculated using approach suggested by Huang et al. (2003). The MPE values from kriging and IDW methods to $95 \%$ confidence intervals for observed mean were: $-4 \%$ and $-6 \%$ for 1999 ; and $-18 \%$ and $-15 \%$ for 2000 , respectively. Using the first criterion suggested by Huang et al. (2003), MPE is less than $\pm 10 \%$ of the observed mean at $95 \%$ confidence intervals; therefore, both methods are acceptable for interpolation for 1999. For 2000, both methods are not acceptable because the MPE from both models is greater than $\pm 10 \%$ of the observed mean at $95 \%$ confidence intervals. However, based on the Huang et al. (2003) second criterion, predicted values by both methods lie in the region of uncertainty (more than $\pm 10 \%$ but less than $\pm 20 \%$ ), both models could be acceptable provided a greater sample set size and better quality data are available.

\section{CONCLUSION}

The following conclusions can be drawn based on the results of this study:

- Both interpolation methods did not reflect true variation of bulk density, particularly the extreme values, and acted as smoothing "filters", however, both methods are suitable for spatial analysis of bulk density. Both interpolators are equally good for spatial description of bulk density. There is very marginal difference between these methods with respect to accuracy and precision.

- Both interpolation methods have the same capability for spatial analysis of bulk density with almost similar absolute average accuracy with a difference of less than $1 \%$.

- Both the interpolation procedures have similar precision capability with less than $0.5 \%$ difference.

- The consistency capability of both interpolators is also similar a difference of less than $2 \%$.

- The average "systematic" errors and their proportion to the total errors are less for IDW weighting method 
than kriging method. Also, average "unsystematic" closer to its RMSE is another indicator of superiority of IDW method over kriging method.

- Inverse distance weighting method, simpler than kriging method, gives competitive and somewhat superior results when an optimal power value is used. Selection of an optimal power value is, however, a difficult task.

- No relation is possible among coefficient of variation, skewness and kurtosis in selecting an appropriate interpolation method for spatial description of bulk density or selecting a power value for IDW method or a semivariogram model for the kriging method.

This study has served as an example of an approach to systematically compare the ability of one or more spatial interpolation methods. By employing the statistical methods described in this study, any interpolation method can be assessed for its ability to accurately describe any spatial data set from the field.

\section{REFERENCES}

Agterberg, F.P. 1984. Trend surface analysis. In Spatial Statistics and Models, eds. G.L. Gaile and C.J. Willmott, 147-171. The Netherlands: D. Reidel Publishing Company. http://dx.doi.org/10.1007/978-94-017-3048-8_8

Barnes, R. 1999. The variogram sill and the sample variance. Mathematical Geology 23(4): 673-378. http://dx.doi.org/10.1007/BF02065813

Bishop, T.F.A. and A.B. McBratney. 2001. A comparison of prediction methods for the creation of field-extent soil property maps. Geoderma 103:149-160. http://dx.doi.org/10.1016/S0016-7061(01)00074-X

Brouder, S.M., B.S. Hofmann and D.K. Morris. 2005. Mapping soil $\mathrm{pH}$ : Accuracy of common soil sampling strategies and estimation techniques. Soil Science Society of America Journal 69: 427-442. http://dx.doi.org/10.2136/sssaj2005.0427

Burrough, P.A. and R.A. McDonnell. 1998. Principals of Geographical Information Systems. New York, NY: Oxford University Press.

Cambardella, C.A. and D.L. Karlen. 1999. Spatial analysis of soil fertility parameters. Precision Agriculture 1: 514. http://dx.doi.org/10.1023/A:1009925919134

Cambardella, C.A., T.B. Moorman, J.M. Novak, T.B. Parkin and D.L. Karlen. 1994. Field-scale variability of soil properties in Central Iowa soils. Soil Science Society of America Journal 58: 1501-1511. http://dx.doi.org/10.2136/sssaj1994.03615995005800 050033x

Carr, J.R. 1995. Numerical Analysis for the Geological Sciences. Eaglewood Cliffs, NJ: Prentice Hall.

Carr, J.R. 2002. Data Visualization in the Geosciences. Upper Saddle River, NJ: Prentice Hall.

Caurso, C. and F. Quarta. 1998. Interpolation methods comparison. Computers \& Mathematics with Applications 35: 109-126. http://dx.doi.org/10.1016/S0898-1221(98)00101-1
Chang, J., D.E. Clay, C.G. Carlson, D. Malo, S.A. Clay, J. Lee and M. Ellsbury. 1999. Precision farming protocols: Part 1. Grid distance and soil nutrient impact on the reproducibility of spatial variability measurements. Precision Agriculture Journal 1: 277289. http://dx.doi.org/10.1023/A:1009921024451

Chatterjee, S., A.S. Hadi and B. Price. 2000. Regression Analysis By Example. 3rd edition. New York, NY: John Wiley \& Sons, Inc.

Delfiner, P. 1976. Linear estimation of non stationary spatial phenomena. In Advanced Geostatistics in the Mining Industry, eds. M. Guarascio, M. David and C. Huijbregts, 49-68. Dordrecht, Holland: D. Reidel Publishing Company. http://dx.doi.org/10.1007/978-94-010-1470-0_4

Deutsch, C.V. 2002. Geostatistical Reservoir Modeling. New York, NY: Oxford University Press.

Ella, V.B., S.W. Melvin and R.S. Kanwar. 2001. Spatial analysis of NO3-N concentration in glacial till. Transactions of the ASAE 44(2): 317-327.

Franzen, W.D. and T.R. Peck. 1995. Field soil sampling density for variable rate fertilization. Journal of Production Agriculture 8: 568-574. http://dx.doi.org/10.2134/jpa1995.0568

Freese, F. 1960. Testing accuracy. Forest Science 6: 139145.

Gambolati, G. and G. Volpi. 1979, A conceptual deterministic analysis of the Kriging technique in hydrology. Water Resources Research 15 (3): 625629. http://dx.doi.org/10.1029/WR015i003p00625

Gaertner, G., P. Parysow and B. Guan. 1996. Projection variance partitioning of a conceptual forest growth model with orthogonal polynomials. Forest Science 42: 474-486.

Goderya, F.S., M.F. Dhab, W.E. Woldt and I. Bogradi. 1996. Spatial patterns analysis of field measured soil nitrate. In Geostatistics for Environmental and Geotechnical Applications, eds. S. Rouhani, R.M. Srivastava, A.J. Desbarats, M.V. Cromer and A.I. Jonson, 248-261. Ann Arbor, MI: ASTM Publications.

http://dx.doi.org/10.1520/STP16125S

Goovaerts, P. 1998. Geostatistical tools for characterizing the spatial variability of microbiological and physicochemical soil properties. Biology and Fertility of Soils 27: 315-334.

http://dx.doi.org/10.1007/s003740050439

Gotway, C.A., R.B. Ferguson, G.W. Hergert and T.A. Peterson. 1996. Comparisons of kriging and inversedistance methods for mapping soil parameters. Soil Science Society of America Journal 60: 1237-1247. http://dx.doi.org/10.2136/sssaj1996.03615995006000 040040x

Gamma Design Software. 2002. GS+TM_ GeoStatics for the Environmental Sciences (version 5.3.2). Plainwell, MI: Gamma Design Software. 
Gupta, N. 2002. Investigation of rainfall-runoff mechanism on field scale. Ph.D. Dissertation. Guelph, ON: School of Engineering, University of Guelph.

Hohn, M.E. 1999. Geostatistics and Petroleum Geology. Dordrecht, The Netherlands: Kluwer Academic Publishers. http://dx.doi.org/10.1007/978-94-0114425-4

Huang, S., Y. Yang and Y. Wang. 2003. A critical look at procedures for validating growth and yield models. In Modelling Forest Systems, eds. A. Amaro, D. Reed and P. Soares, 271-293. Wallingford, UK: CABI.

Isaaks, E.H and R.M. Srivastava. 1989. An Introduction to Applied Geostatistics. New York, NY: Oxford University Press.

Johnson, V.M., R.C. Tuckfield, M.N. Ridley and R.A. Anderson. 1996. Reducing the sampling frequency of ground-water monitoring wells. Environmental Science and Technology 30(1): 355-358.

http://dx.doi.org/10.1021/es950335u

Kanji, G.K. 1993. 100 Statistical Tests. London, UK: SAGE Publications.

Kitanidis, P.K. 1997. Introduction to Geostatistics: Applications in Hydrogeology. New York, NY: Cambridge University Press.

http://dx.doi.org/10.1017/CBO9780511626166

Kravchenko, A.N. 2003. Influence of spatial structure on accuracy of interpolation methods. Soil Science Society of America Journal 67: 1564-1571.

http://dx.doi.org/10.2136/sssaj2003.1564

Kravchenko, A and D.G. Bullock. 1999. A comparative study of interpolation methods for mapping soil properties. Agronomy Journal 91: 393-400.

http://dx.doi.org/10.2134/agronj1999.0002196200910 $0030007 \mathrm{x}$

Lam, NS-N. 1983. Spatial interpolation methods: a review. The American Cartographer 10(2): 129-149.

http://dx.doi.org/10.1559/152304083783914958

Lapen, D.R and H.N. Hayhoe. 2003. Spatial analysis of seasonal and annual temperature and precipitation normals in Southern Ontario, Canada. Journal of Great Lake Research 29: 529-544.

http://dx.doi.org/10.1016/S0380-1330(03)70457-2

Laslett, G.M., A.B. McBratney, P.J. Pahl and Hutchinson. 1987. Comparioson of several spatial prediction methods for soil pH. Journal of Soil Science 38: 325341.

http://dx.doi.org/10.1111/j.1365-2389.1987.tb02148.x

Laslett, M. 1994. Kriging and splines: An empirical comparison of their predictive performance in some applications. Journal of the American Statistical Association 89: 391-400.

http://dx.doi.org/10.1080/01621459.1994.10476759

Legates, D.R and G.J McCabe. 1999. Evaluating the use of "goodness-of-fit" measures in hydrologic and hydroclimatic model validation. Water Resources Research 35(1): 233-241.

http://dx.doi.org/10.1029/1998WR900018
MacEachren, A.M and J.V. Davidson. 1987. Sampling and Isometric Mapping of Continuous Geographic Surfaces. The American Cartographer 14(4): 299-320. http://dx.doi.org/10.1559/152304087783875723

McBratney, A.B and R. Webster. 1986. Choosing function for semi-variograms of soil properties and fitting them to sampling estimates. Journal of Soil Science 37: 617639.

http://dx.doi.org/10.1111/j.1365-2389.1986.tb00392.x

McRoberts, R.E. 1996. Estimating variation in field crew estimates of site index. Canadian Journal of Forest Research 26: 560-565.

http://dx.doi.org/10.1139/x26-064

Mowrer, H.T and W.E. Frayer. 1986. Variance propagation in growth and yield projection. Canadain Journal of Forest Research 16: 1196-1200.

http://dx.doi.org/10.1139/x86-213

Mueller, T.G., F.J. Pierce, O. Schabenberger and D.D. Warncke. 2001. Map quality for site-specific fertility management. Soil Science Society of America Journal 65: 1547-1558.

http://dx.doi.org/10.2136/sssaj2001.6551547x

Naoum, S and I.K. Tsanis. 2004. Ranking spatial interpolation techniques using a GIS-based DSS. Global NEST: the International Journal 6(1): 1-20.

Pillsbury, N.H., P.M. McDonald and V. Simon. 1995. Reliability of tanoak volume equations when applied to different areas. Western Journal of Applied Forestry 10(2): 72-78.

Prevost, M. 2004. Predicting soil properties from organic matter content following mechanical site preparation of forest soils. Soil Science Society of America Journal 68: 943-949.

http://dx.doi.org/10.2136/sssaj2004.9430

Sajid, A.H. 2009. Investigation of rainfall-runoff process in relation to soil physical and hydraulic properties. Ph.D. Dissertation. Guelph, ON: School of Engineering, University of Guelph.

Schloeder, C.A., N.E. Zimmerman and M.J. Jacobs. 2001. Comparison of methods for interpolating soil properties using limited data. Soil Science Society of America Journal 65: 470-479.

http://dx.doi.org/10.2136/sssaj2001.652470x

Golden Software Inc. 2002. Surfer® (ver. 5.3.2). Golden Software Inc., Golden, CO: Golden Software Inc.

Tukey, J.W. 1977. Exploratory Data Analysis. London, UK: Addison-Wesley.

Voltz, M and R. Webster. 1990. A comparison of Kriging, cubic splines and classification for predicting soil properties from sample information. Journal of Soil Science 31: 505-524.

Vos, B.D., M.V. Meirvenne, P. Quataert, J. Deckers and B. Muys. 2005. Predictive quality of pedotransfer functions for estimating bulk density of forest soils. Soil Science Society of America Journal. 69 (2): 500510. http://dx.doi.org/10.2136/sssaj2005.0500 
Warrick, A.W., R. Zhang, M.K. El-Harris and D.E. Myers. 1988. Direct comparisons between kriging and other interpolators. In Proceedings of the Validation of Flow and Transport Models in the Unsaturated Zone, 505-510. Ruidoso, NM. May 23-26.

Weber, D and E. Englund. 1994. Evaluation and comparison of spatial interpolators II. Mathematical Geology 26: 589-603.

http://dx.doi.org/10.1007/BF02089243

Webster, R and M.A. Oliver. 2001. Geostatistics for Environmental Scientists. West Sussex, England: John Wiley \& Sons Ltd.

Willmott, C.J. 1984. On the Evaluation of Model Performance in Physical Geography. In Spatial Statistics and Models, eds. G.L. Gaile and C.J. Willmott, 443-460. Dordrecht, Holland: D. Reidel Publishing Company.

http://dx.doi.org/10.1007/978-94-017-3048-8_23
Willmott, C.J. 1981. On the validation of models. Physical Geography 2(2): 184-194.

Woldt, W., 1990, Ground water contamination control: detection and remedial planning, Ph.D. Dissertation. Lincoln, NE: Department of Civil Engineering, University of Nebraska - Lincoln.

Wollenhaupt, N.C., R.P. Wolkowski and M.K. Clayton. 1994. Mapping soil test phosphorus and potassium for variable-rate fertilizer application. Journal of Production Agriculture 7:441-448 http://dx.doi.org/10.2134/jpa1994.0441

Yates, S.R and M.V. Yates. 1990. A user's manual for the GEOPACK (version 1.0) Geostatistical software, EPA/600/8-90/004. 70. Ada, OK: United States Environmental Protection Agency.Table 1: Summary statistics of observed and interpolated data for bulk density. 